Family Medicine and Community Health

\title{
Physical exam: where's the evidence? A medical student's experience
}

\author{
Scott M Seki, ${ }^{1}$ Katharine C DeGeorge, ${ }^{2}$ Margaret L Plews-Ogan, ${ }^{3}$ \\ Andrew S Parsons ${ }^{3}$
}

To cite: Seki SM, DeGeorge KC, Plews-Ogan ML, et al. Physical exam: where's the evidence? A medical student's experience. Fam Med Com Health 2020;8:e00284. doi:10.1136/ fmch-2019-000284
Check for updates

(C) Author(s) (or their employer(s)) 2020. Re-use permitted under CC BY-NC. No commercial re-use. See rights and permissions. Published by BMJ.

${ }^{1}$ University of Virginia School of Medicine, Charlottesville, Virginia, USA

${ }^{2}$ Department of Family Medicine, University of Virginia, Charlottesville, Virginia, USA

${ }^{3}$ Department of Medicine, University of Virginia, Charlottesville, Virginia, USA

Correspondence to Dr Katharine C DeGeorge; KD6FP@hscmail.mcc.virginia. edu
It was not so long ago that an attending physician accused me of the following: 'you're advocating for the elimination of the physical exam from medicine!' We were on rounds and debating the objectivity and merit of a single observer non-blinded prestudy/poststudy, the Bush-Francis Catatonia Scale, as a means of measuring clinical status after an Ativan challenge. 'The kind of improvement you all are expecting is so obvious that the scale becomes obsolete', I argued, 'And furthermore, in the gray area, improvements based on the scoring system don't seem to approximate improvements in patient symptoms'. I was fresh off of finishing my $\mathrm{PhD}$ in neuroscience, a little too confident and a little too keen for a debate; it is how we were trained to survive in graduate school and I was still adjusting back to a slightly less contentious style of living. As third year of medical school came to a close, I found myself feeling extremely grateful to the other M3s, patients, providers and more, all of whom played essential roles in my maturation into an effective medical student. I sought out an opportunity to pay it forward through a project related to medical education and was presented with the following: 'The physical exam manual [used to teach my institution's medical students] is badly in need of updating'. Full circle. In this reflection, I share my experience creating an evidence-based physical exam manual and how, in so doing, I came to appreciate even more the critical importance of the physical exam as a tool for patient care.

Steven McGee's Evidence-Based Physical Diagnosis manual was a critical resource for the construction of this new evidence-based physical exam manual. ${ }^{1}$ I enjoyed taking key manoeuvres for diagnosis taught to me on the wards and assessing their purported utility based on Dr McGee's compilation of a great many studies interrogating likelihood ratios and positive/negative predictive values for each technique. It came as no surprise that many of the manoeuvres we are taught are strongly supported in the literature, especially when used as diagnostic aids within more comprehensive triaging scoring systems (eg, clinical prediction rules). An example is the Alvarado score, one method for predicting acute appendicitis in the patient who presents with abdominal pain. By incorporating subjective and objective elements of patient history and presentation, one can use the Alvarado score to do a reasonably good job of predicting the presence or absence of appendicitis in a population with a high pretest probability of having this ailment, thereby facilitating the optimal allocation of resource-intense interventions to those who require them most. ${ }^{2}$ As in the case of reading the original Alvarado paper, it was highly rewarding to learn the origin story of each exam manoeuvre as well as the history and extent of its validation. By extending my repertoire from knowing how to do a specific manoeuvre to understanding the broader utility of its contribution to an overall diagnosis, I also came to feel that my physical interactions with patients were much more consistent with the oath I took on day 1 to 'first do no harm'. That patients allow me to touch them for the sake of not only their diagnosis but also my learning is an honour, and thus it seemed only right that I learnt not only how to touch but also when and why. I hope that creating an evidence-based physical exam manual for my institution contributes to this spirit of patient care.

During my journey in making this exam manual, I spent quite a bit of time considering the rationale behind paring down the list of delineated manoeuvres to only those with evidence-based diagnostic value. I felt torn between ensuring that the manual was viewed as being comprehensive when I was omitting classically taught manoeuvres without strong evidence bases, such as the psoas and obturator signs in the diagnosis of appendicitis. ${ }^{1} \mathrm{I}$ 
was inspired by the extent to which Canada has invested in the study and development of evidence-based clinical prediction tools requiring only a simple physical exam, ultimately saving an untold number of healthcare dollars without forsaking diagnostic accuracy. The Ottawa Knee, Ankle and C-spine rules have surely set the standard for minimising unnecessary resource use and exposure to harm by maximising the utility of the physical exam and, even better, as applied to a broad swath of the population. While these Canadian prediction rules are strictly reliant on a few simple evidence-based physical exam manoeuvres, they remain highly effective and broadly generalisable, thereby demonstrating the power of a physical exam that is efficient and purposefully streamlined.

I could not help but wonder if streamlining the physical exam brings us one step closer to an emergency department where patients input a few signs or symptoms and a computer triages them accordingly. It seems as though medicine and society are willing to allow technology into high-level aspects of patient care, such as employing machine learning to generate models that can predict and prevent a specific patient's demise in an intensive care unit or using genetics and rationally designed pharmaceuticals to treat a specific patient's cancer. How about the use of technology in the initial patient encounter however? Non-invasive blood pressure measurements are more accurate when taken by a machine than by a person, and cardiac auscultation can now be performed by a computer. ${ }^{34}$ Returning to the example of the Alvarado score, an argument could be made that, on reviewing vitals, laboratory work, patient history and a brief conversation with the patient, a skilled provider could generate an impression about the necessity of escalating care without ever needing to place hands on the patient. In fact, perhaps this would lead to fewer missed diagnoses when appendices are not positioned just so in an abdominal cavity that is, generally speaking, likely more robust than those encountered by Alvarado in his original paper. At the very least, it would preclude patients with abdominal pain suspicious for appendicitis from the cruelties of someone in whom they have placed their trust, betraying them by testing for rebound tenderness. In the case of suspected appendicitis, it would be interesting to design a prospective study that called into question the necessity of a provider physically touching a patient, or perhaps even interacting with the patients at all, to facilitate cost-effective triaging, less influenced by intraprovider/ interprovider variation and biases, towards downstream imaging or operative intervention. Depending on the results, perhaps that would free providers to focus on more medically complex patients and thus facilitate optimal allocation of likely the most limited resource in the emergency department. Then again, is this the kind of medicine that we are comfortable teaching, doing and exalting?

As determined by a recent study in the Annals of Family Medicine, perhaps something not emphasised enough by focusing on the physical exam as an evidence-based diagnostic tool is the integral role it plays in establishing and building patient-provider relationships. ${ }^{5}$ Numerous studies show that patients are more satisfied with their care when a provider performs a physical examination for practical reasons of assisting with diagnosis as well as for the symbolic reason of feeling cared for. ${ }^{67}$ In this way, the physical exam can be viewed not only as a diagnostic tool but also as an important form of non-verbal communication, a known driver of patient satisfaction. ${ }^{8}$ The evolving discussion of the appropriateness of touch within (and especially beyond) the exam room provides an additional layer of complexity that merits an intense degree of training for practitioners who must navigate the nuances of physical boundaries in the context of medical practice. Focusing on the unique ways of physically interacting with patients is likely to be just as important as focusing on the specific aspects of the physical interaction itself. ${ }^{9}$ There is compelling evidence to support improving patient experience as a means of improving patient outcomes, if only by increasing the likelihood of routine medical follow-up and reaping the benefits of the Hawthorne effect. ${ }^{10}$ While the evidence relating specific exam manoeuvres to specific diagnoses will always be hampered for reasons related to restricted generalisability (eg, an exam manoeuvre that is only valid in non-pregnant adults), difficulties with patient-provider communication (eg, the definition of $10 / 10$ pain) and more, there is an overwhelming amount of evidence to support the use of the physical exam as a communication and relationship-building tool between patient and provider. This is an aspect of the physical exam that, as of yet, there is no technology to replace.

My institution now has a new physical exam manual, complete with illustrations to assist with the technical aspects of manoeuvre performance and evidence to encourage the use of only the most validated means of physical interaction to assist with ultimate diagnosis. One year ago, my attending physician asked me to explain my feelings about the physical exam as a diagnostic tool. Having created this physical exam manual, I now have a greater understanding of and appreciation for this challenge. I think I have always agreed that the physical exam can play an important role in patient diagnosis and the optimisation of healthcare use costs. What I did not expect to gain by studying the evidence supporting individual physical exam manoeuvres was a greater appreciation for it as a tool of communication. Likewise, I hope my newly constructed manual not only augments the teaching of an evidence-based physical exam but also serves to highlight the importance of the patient-provider relationship: the performance of the performance. After all, the relationship-building aspect of the physical exam is likely the most evidence-based manoeuvre of all.

Twitter Katharine C DeGeorge @evidentlyMD

Contributors SMS is a fourth-year medical student interested in medical education. He was tasked with redesigning a physical exam manual for teaching. ASP and MLP-O direct the Clinical Skills Course for the School of Medicine. KCD is an expert in evidence-based physical diagnosis. 
Funding The authors have not declared a specific grant for this research from any funding agency in the public, commercial or not-for-profit sectors.

Competing interests None declared.

Patient consent for publication Not required.

Provenance and peer review Not commissioned; externally peer reviewed.

Open access This is an open access article distributed in accordance with the Creative Commons Attribution Non Commercial (CC BY-NC 4.0) license, which permits others to distribute, remix, adapt, build upon this work non-commercially, and license their derivative works on different terms, provided the original work is properly cited, appropriate credit is given, any changes made indicated, and the use is non-commercial. See: http://creativecommons.org/licenses/by-nc/4.0/.

\section{REFERENCES}

1 McGee SR. Evidence-Based physical diagnosis. Elsevier, 2018.

2 Alvarado A. A practical score for the early diagnosis of acute appendicitis. Ann Emerg Med 1986;15:557-64.
3 Roerecke M, Kaczorowski J, Myers MG, et al. Comparing automated office blood pressure readings with other methods of blood pressure measurement for identifying patients with possible hypertension: a systematic review and meta-analysis. JAMA Intern Med 2019;179, :351.

4 Thompson WR, Reinisch AJ, Unterberger MJ, et al. Artificial Intelligence-Assisted auscultation of heart murmurs: validation by virtual clinical trial. Pediatr Cardiol 2019;40:623-9.

5 Kelly MA, Freeman LK, Dornan T, et al. Family physicians' experiences of physical examination. Ann Fam Med 2019;17:304-10.

6 Kravitz RL, Cope DW, Bhrany V, et al. Internal medicine patients' expectations for care during office visits. J Gen Intern Med 1994;9:75-81.

7 Kadakia KC, Hui D, Chisholm GB, et al. Cancer patients' perceptions regarding the value of the physical examination: a survey study. Cancer 2014;120:2215-21.

8 DiMatteo MR, Taranta A, Friedman HS, et al. Predicting patient satisfaction from physicians' nonverbal communication skills. Med Care 1980;18:376-87.

9 Kneebone R. Getting back in touch. Lancet 2018;391:1348.

10 McCarney R, Warner J, lliffe S, et al. The Hawthorne effect: a randomised, controlled trial. BMC Med Res Methodol 2007;7:30. 